> of Life Scientists. The opinion article, she says, was prompted by the aftermath of the US budget sequester - across-the-board funding cuts that have further strained research budgets and tightened the number of available research posts. The authors call for US universities to gradually cut back the number of students they enrol in biomedical $\mathrm{PhD}$ courses and to hire staff scientists, instead of postdocs and graduate students, for day-to-day lab work. More staff-scientist positions would benefit people with PhDs who want to do bench science, and would help principal investigators by providing lab-management assistance (see Nature 510, 433-434; 2014).

Current NIH director Francis Collins says that the agency has begun to address some of these issues, by giving postdocs a $7 \%$ pay rise in 2014 and creating a new award for young cancer researchers, for instance. More such awards are in the works, he says.

However, Collins is not convinced that there is an oversupply of life science PhDs. $\mathrm{He}$ is also reluctant to alter the way graduate students and postdocs are funded in an attempt to control the $\mathrm{PhD}$ pipeline. Shifting them to different types of grant "would be an enormous administrative challenge and would have serious consequences, such as excluding foreign trainees in our workforce", he says.

Collins agrees with the recommendation that universities tell trainees about a range of career options, not just academic research. Last year, the NIH launched the 'Broadening Experiences in Scientific Training' programme to help universities do just that. Information - about both job possibilities and career outcomes - helps trainees to make informed decisions about which path to take, says Collins.

Toby Smith, vice-president of policy for the American Association of Universities in Washington DC, agrees. He says that deans in the association's membership have begun to ask $\mathrm{PhD}$ graduates about what jobs they end up getting. The association is holding a workshop on graduate education in November and it encourages universities to gather data on their alumni.

Keith Micoli, chairman of the US National Postdoctoral Association in Washington DC, agrees that the existing academic-research set-up keeps postdocs dependent on their lab heads for increasingly longer periods. Controlling the supply of young scientists could help, he says, although he worries about unintended consequences. "My fear," he says, "is that we would just weaken the US science pipeline."

Paul Smaglik is assistant editor of Nature Careers.

\title{
COLUMN
}

\section{A wake-up call}

\section{Graduate students must educate themselves and others about academia's dim job prospects, says Jessica Polka.}

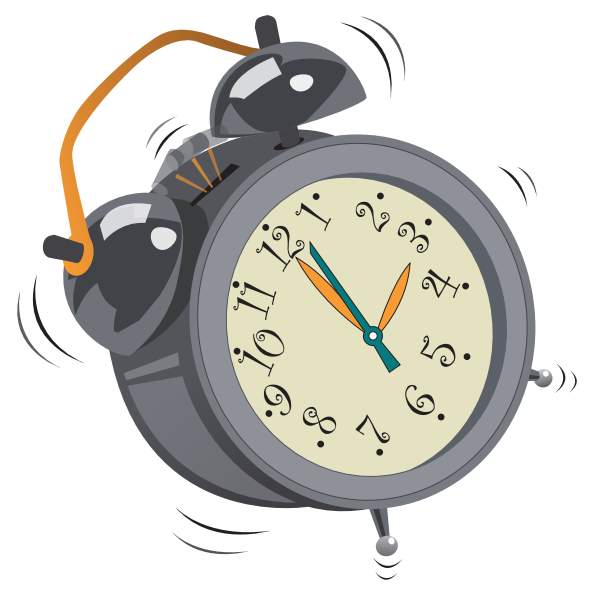

$\mathrm{M}$ any graduate students in the biomedical sciences dream of becoming academic researchers. Yet if current employment trends continue, their odds of landing a tenure-track post in the United States are less than $10 \%$, according to data from the US National Institutes of Health (NIH) and the US National Science Foundation. In sum: faculty research positions in this discipline have become an 'alternative' career option.

Many biomedical graduate students and their advisers remain woefully ignorant of this development, even though information on the changing workforce is freely available. To consolidate these numbers into a simple picture, I assembled key statistics on the outlook for biomedical $\mathrm{PhD}$ holders into an infographic that appeared in April in The ACSB Post, the blog for the American Society for Cell Biology (see go.nature.com/vh1ewm). The fact that the trends surprised some of my colleagues suggests that the information has not been sinking in.

Many young scientists, myself included, come to realize the severity of the academic-workforce supply issue only late in their training. This innocence is an unfortunate but natural consequence of the environment we have created.

When a student is applying for a biomedical $\mathrm{PhD}$, she or he is unlikely to learn from programme administrators about the dim prospects for an academic career. Data on trainee outcomes are not readily available, and administrators are not currently required to collect them. The statistics that do exist are sobering, and most university interviewers do not see them as selling points.

Even if provided, the data may at first seem irrelevant to the students. The average trainee takes 7 years to complete a $\mathrm{PhD}$ and 4 years to do a postdoc, according to NIH data, and the volatility of the funding climate makes it impossible to predict the job market 11 (or more) years in advance. The historical context, however, presents a clear picture of an unsustainable system in which the halcyon days are long over.

Also a possibility is that many of our heads are in the sand because we have stuck them there. The numbers sound bad, but we persuade ourselves that they do not apply to us. In a perfect world, we would not have to worry about job security; in the real one, our ignorance seems self-protective. But it isn't.

It behooves us to not only educate ourselves about the dysfunctions of the system, but also participate in discussions of what to do about it. This is especially true for those of us hellbent on a faculty position, because at least some of us will be shaping the culture of science. Conversations about creating a sustainable research enterprise are increasingly arising in policy groups, prominent journals, national meetings and online. But even though they are major stakeholders, trainees are conspicuously absent. To make our voices heard, we need to engage in more discussions within scientific societies, student and postdoctoral organizations and online.

Trainees who are vocal about sustainability issues will also help to raise awareness among their peers and the people they mentor, and set a standard of awareness that - we would hope - will one day form a part of US academic culture.

Finally, young scientists must fundamentally rethink their approach to graduate training and postdoctoral appointments. We must see this stage as the only chance many of us will ever have to do biomedical research, rather than as preparation for a well-defined career. But while we take advantage of this unique opportunity, we should also prepare for the future. We must actively explore all professional possibilities; simultaneously, we should advocate for strengthening the future of US science by making it a more attractive career choice. The catalyst for both these changes will be clear dissemination of information on training outcomes to students - and the sooner we start, the better.

Jessica Polka is a postdoctoral researcher in systems biology at Harvard Medical School in Boston, Massachusetts. 